\title{
STUDI EXPERIMEN KUAT TEKAN BETON DENGAN MEMANFAATKAN LIMBAH KERAMIK DAN BATA MERAH
}

\author{
Satria Febby Romadhoni *1, Ahmad Ridwan 2 ${ }^{2}$, Sigit Winarto ${ }^{3}$, Agata Iwan Candra ${ }^{4}$. \\ 1,2,3 Fakultas Teknik, Universitas Kadiri. \\ e-mail:*1 romadhoni140@gmail.com, 22ahmad ridwan@unik-kediri.ac.id,3 \\ sigit.winarto@unik-kediri.ac.id, ${ }^{4}$ iwan_candra@unik-kediri.ac.id.
}

\begin{abstract}
Normal concrete sample (1) has a compressive strength of $222.22 \mathrm{~kg} / \mathrm{cm}$, normal concrete (2) has a compressive strength of $242.933 \mathrm{~kg} / \mathrm{cm}$, concrete using a mixture of ceramic $21 \%$ and red brick $7 \%$ sample (1) has a compressive strength of $177.911 \mathrm{~kg} / \mathrm{cm}$, concrete using a mixture of $21 \%$ Ceramics and red brick $7 \%$ sample (2) has a compressive strength of $189.777 \mathrm{~kg} / \mathrm{cm}$, concrete using a mixture of $10 \%$ Ceramics and red brick $4 \%$ sample (1) has a compressive strength of $204.667 \mathrm{~kg} / \mathrm{cm}$, concrete which uses a mixture of $10 \%$ Ceramics and red brick 4\% sample (2) has a compressive strength of 137,333 $\mathrm{kg} / \mathrm{cm}$. It shows that the compressive strength of concrete decrease from increasing the volume of ceramics because the ceramic surface cannot bind perfectly. The highest $K-204,667$ with a mixture of $10 \%$ ceramics and $4 \%$ red brick and 28-day-old concrete, while to reach the K-250, is very far away. Of the 6 samples, the average reached K-195,807.
\end{abstract}

Keywords: Concrete, Red Brick, Ceramic Waste, Compressive Strength

\begin{abstract}
Abstrak
Sampel beton normal (1) memiliki kuat tekan 222,22 kg / cm, beton normal (2) memiliki kuat tekan 242.933 $\mathrm{kg} / \mathrm{cm}$, sampel beton menggunakan campuran keramik $21 \%$ dan bata merah sampel $7 \%$ (1) memiliki kuat tekan $177.911 \mathrm{~kg} / \mathrm{cm}$, sampel beton menggunakan campuran keramik $21 \%$ dan bata merah $7 \%$ (2) memiliki kuat tekan $189.777 \mathrm{~kg} / \mathrm{cm}$, sampel beton campuran 10\% Keramik dan bata merah 4\% (1) kuat tekan $204.667 \mathrm{~kg} / \mathrm{cm}$, sampel beton yang menggunakan campuran Keramik 10\% dan sampel bata merah 4\% (2) memiliki kuat tekan $137.333 \mathrm{~kg} / \mathrm{cm}$. Ini menunjukkan bahwa Kuat tekan beton semakin berkurang dari bertambahnya volume keramik, karena permukaan keramik tidak bisa mengikat dengan sempurna. K204.667 tertinggi dengan campuran 10\% keramik dan 4\% bata merah serta beton berumur 28 hari, sedangkan untuk mencapai K-250 sangat jauh jauh. Dari 6 sampel tersebut rata-rata mencapai K-195.807.
\end{abstract}

Kata Kunci : Beton, Bata Merah, Limbah Keramik, Kuat Tekan 


\section{PENDAHULUAN}

Beton yaitu sebuh bahan bangunan koposit yang terbuat dari kombinasi agregat dan pengikat yaitu semen. Semen yang sering di gunakan yaitu semen portland,yang terdiri dari agregat mineral,air dan semen, [1][2].

Berdasarkan kuat tekannya, mutu beton dibagi menjadi 3 jenis, yaitu beton mutu biasa, beton mutu tinggi,dan beton mutu sangat tinggi merupakan pilihan yang paling tepat untuk membuat bangunan bertingkat tinggi, [3].

Penelitian yang di lakukan adalah dengan memberikan bahan tambahan atau Admixture yaitu bahan keramik unruk pengganti agregat kasar dan bata merah untuk penggaganti agregat halus, [4][5]. Dalam penelitian ini keramik di ambil dari limbah renofasi rumah di sekitar Kabupaten Blitar.atau dari pabrik keramik.

Limbah keramik maupun bata merupakan salah satu limbah yang dihasilkan dari perenofasian rumah tinggal maupun gedung di Kota Blitar yang terbuang sia-sia. Oleh karena itu, pada penelitian ini akan mencoba mengaplikasikan pemanfaatan linbah keramik maupun bata sebagai bahan aternatif yang diharapkan dapat menggantikan bahan penyusun beton,[6].

Berdasarkan latar belakang yang di jabarkan di atas,maka di rumuskan masalah sebagai berikut:

1. Mengetahui seberapa besar kuat tekan beton menggunakan pecahan keramik dan bata merah ? [7].

2. Bagaimana perbedaan kuat tekan beton normal dan beton campuran keramik dan bata merah?

3. Bagaimana pegaruh penambahan volume campuran kramik dan bata merah yang bervariasi ( $21 \%$ kramik dan $14 \%$ bata merah, $4 \%$ kramik dan $10 \%$ bata merah) ? [8].

Beton adalah bahan bangunan yang paling sering di jumpai di negara ini. Kadang beton divariasi dengan adanya tulangan atau baja untuk menjadi bahan untuk penguat beton itu sendiri, [9][10]. Dapat disimpulkan bahan pembuatan beton terdiri dari air, semen, pasir dan agregat kasar (krikil), [11].

Dan di penelitian ini menggunakan keramik dan bata merah untuk campuran beton itu sendiri. Keramik untuk bahan campuran agregat kasar sedangkan bata merah untuk campuran agregat halus, [12][13].

\section{METODE PENELITIAN}

\subsection{Bahan.}

Material penyusun merupakan material bahan yang dibutuhkan pada pembuatan Beton dan pada penelitian ini bahan material yang akan digunakan diantaranya adalah sebagai berikut, [14]: 


\section{A. Limbah Keramik}

Limbah pecah kramik adalah sisa atau pecah kramik dari lantai sebuah bangunan. Limbah pecah kramik digunakan dalam pembuatan beton sebagai agregat kasar, [15][16].

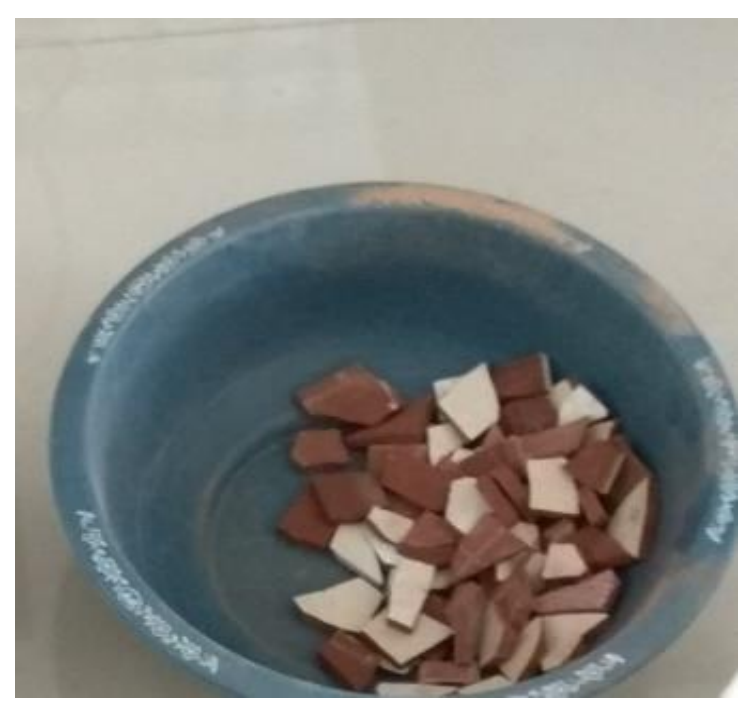

Sumber : Dokumentasi Pribadi

Gambar 1. Limbah Keramik

B. Serbuk Bata Merah

Batu bata merah adalah salah satu bahan material pembuatan dinding. Batu bata tersebut terbuat dati tanah liat yang di panaskan atau di bakar sampai berwarna merah.

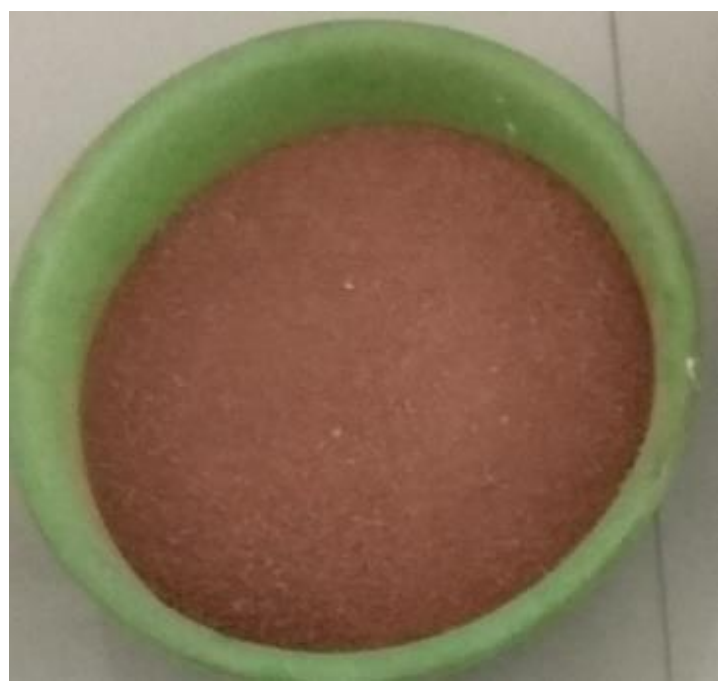

Sumber : Dokumentasi Pribadi

Gambar 2. Serbuk Bata Merah

C. Semen

Semen sangat penting untuk bahan pelekat beton, adalah semen portland jenis gresik dengan kemasan $50 \mathrm{~kg}$ yang ada di pasaran, [17][18]. 


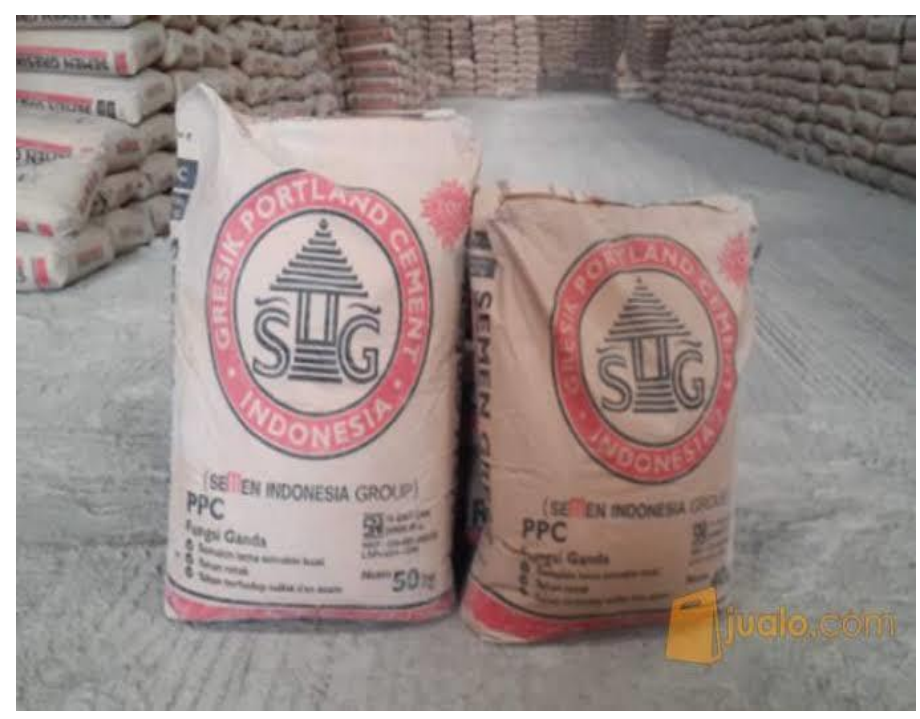

Sumber : jualo.com

Gambar 3. Semen PC

D. Agregat Halus

Agregat yang di gunakan sebagai agregat halus merupakan pasir yang terdapat di sekitar lokasi Limbah kramik maupun bata merah, [19][20].

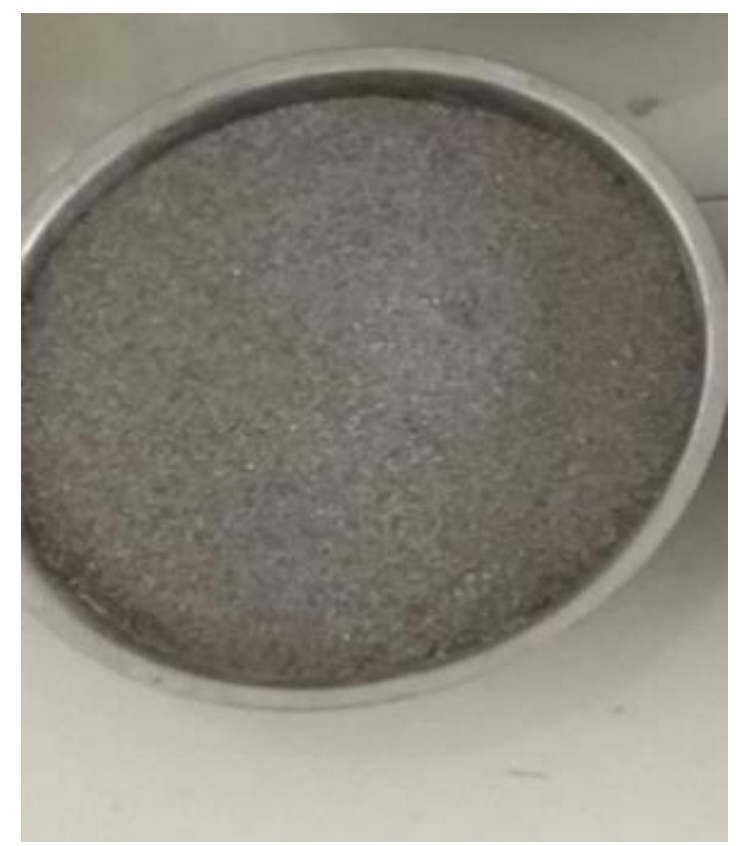

Sumber : Dokumentasi Pribadi

Gambar 4. Agregat Halus

E. Agregat Kasar

Dalam penelitian ini di gunakan agregat kasar yang berasaldari sungai Berantas Blitar,Jawatimur dengan ukuran diameter minimal 20mm, [21][22]. 


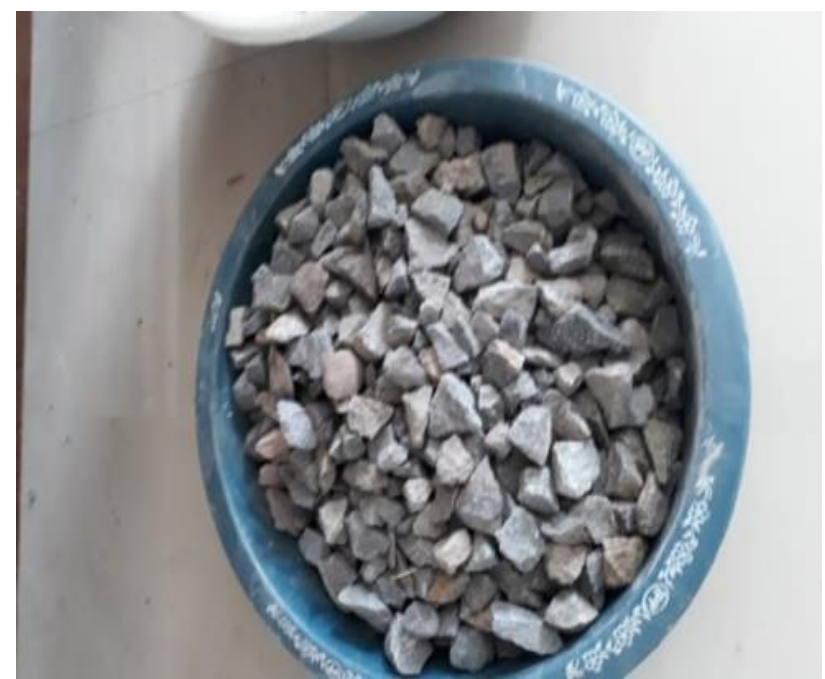

Sumber : Dokumentasi Pribadi

\section{Gambar 5. Agregat Kasar}

\section{F. Air}

Air merupakan bahan wajib untuk pembuat beton, [23]. Karena air mempunyai peranan penting dalam pencampuran beton, maka air tidak dapat di tambahkan sembarangan dalam pengadukan mortal, [24].

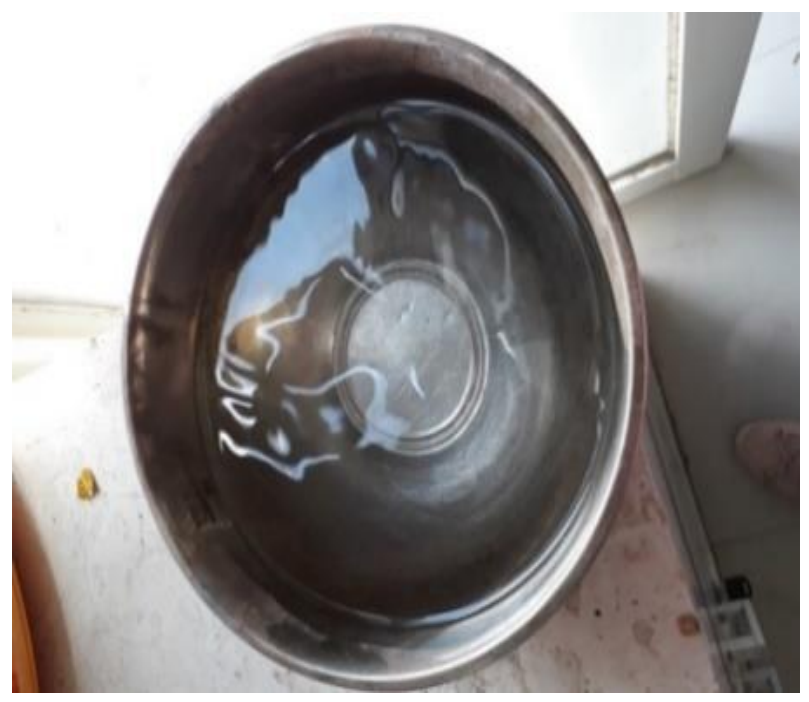

Sumber : Dokumentasi Pribadi

Gambar 6. Air

\section{HASIL DAN PEMBAHASAN}

\subsection{Hasil Pengujian Gradasi Kasar}

Hasil Pengujian Gradasi Kasar dapat dilihat pada tabel 1. 
Tabel 1. Data dan Perhitungan Pengujian Gradasi Agregat Kasar

\begin{tabular}{|c|c|c|c|c|c|}
\hline No & $\begin{array}{c}\text { Lubang } \\
\text { Ayakan } \\
(\mathrm{mm})\end{array}$ & $\begin{array}{c}\text { Berat } \\
\text { Tertinggal } \\
(\text { gram })\end{array}$ & $\begin{array}{c}\text { Berat } \\
\text { Tertinggal } \\
(\%)\end{array}$ & $\begin{array}{c}\text { Berat } \\
\text { Tertinggal } \\
\text { Komulatif }(\%)\end{array}$ & $\begin{array}{c}\text { Persen Lolos } \\
\text { Komulatif } \\
(\%)\end{array}$ \\
\hline 1 & 38,1 & & 0 & 0 & 100 \\
\hline 2 & 25,4 & & 0 & 0 & 100 \\
\hline 3 & 19,1 & 1155 & 57,75 & 57,75 & 42,25 \\
\hline 4 & 12,7 & 690 & 34,5 & 92,25 & 7,75 \\
\hline 5 & 9,52 & 140 & 7 & 99,25 & 0,75 \\
\hline 6 & 4,76 & 15 & 0,75 & 100 & 0 \\
\hline 7 & 2,36 & & 0 & 100 & \\
\hline 8 & 1,19 & & 0 & 100 & \\
\hline 9 & 0,59 & & 0 & 100 & \\
\hline 10 & 0,42 & & 0 & 100 & \\
\hline 11 & Sisa & 0 & 0 & 100 & \\
\hline \multicolumn{7}{|l}{ Jumlah } & 2000 & 100 & 349,25 & \\
\hline
\end{tabular}

Sumber : Analisa Pengamatan

Tabel 2. Hasil Analisa Gradasi Agregat Kasar

\begin{tabular}{|c|c|c|c|}
\hline No & $\begin{array}{c}\text { Lubang } \\
\text { Ayakan } \\
(\mathrm{mm})\end{array}$ & $\begin{array}{l}\text { Berat } \\
\text { Tertinggal } \\
(\%)\end{array}$ & $\begin{array}{c}\text { SNI } \\
\text { Uk. Maks } 40 \mathrm{~mm} \\
(\%)\end{array}$ \\
\hline 1 & 38,1 & 0 & $95-100$ \\
\hline 2 & 25,4 & 0 & \\
\hline 3 & 19,1 & 57,75 & $35-70$ \\
\hline 4 & 12,7 & 34,5 & \\
\hline 5 & 9,52 & 7 & $10-40$ \\
\hline 6 & 4,76 & 0,75 & $0-5$ \\
\hline 7 & 2,36 & 0 & \\
\hline 8 & 1,19 & 0 & \\
\hline 9 & 0,59 & 0 & \\
\hline 10 & 0,42 & 0 & \\
\hline 11 & Sisa & 0 & \\
\hline \multicolumn{2}{|c|}{ Jumlah } & 100 & \\
\hline
\end{tabular}

Sumber : Analisa Pengamatan

Pada tabel 2 menunjukkan hasil uji agregat kasar yang di uji di laboraturium Universitas Kadiri.

Dari tabel 2 di peroleh grafik gradasi agregat kasar yang dapat di lihat pada gambar 7 . 


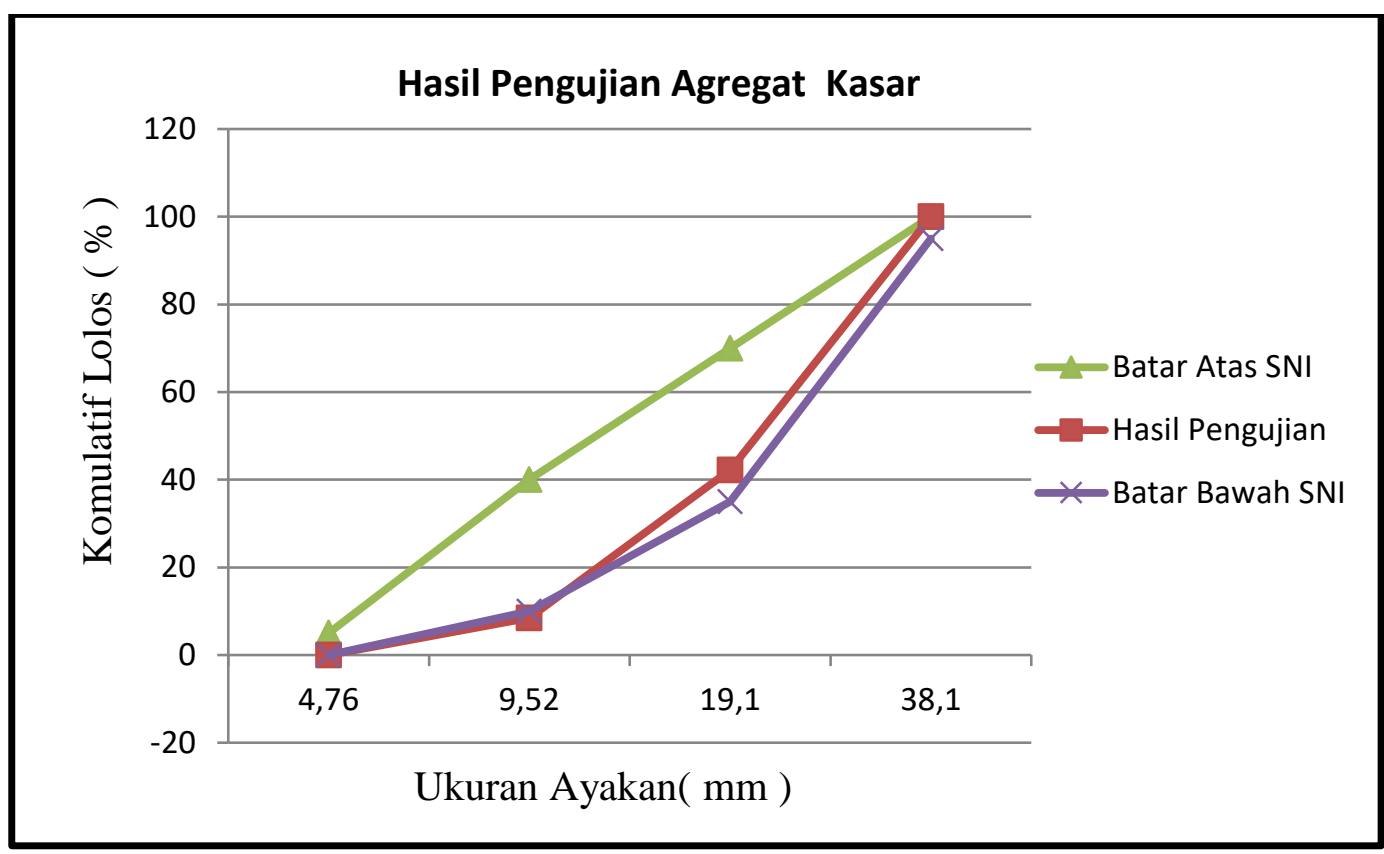

Sumber : Analisa Pengamatan

Gambar 7. Grafik hasil pengujian Gradasi Agregat Kasar

Dari tabel 1 dan 2, serta gambar 7 dapat disimpulkan bahwa agregat kasar yang di gunakan dalam penelitian ini sudah memenuh SNI 03-2834-2000 dengan ukuran maksimum agregat kasar $40 \mathrm{~mm}$.

\subsection{Hasil Kuat Tekan}

Hasil pengujian kuat tekan beton umur 28 hari untuk setiap variasi campuran benda uji, diperlihatkan dalam Tabel 3

Tabel 3. Hasil Uji Kuat Tekan Beton

\begin{tabular}{|c|c|c|c|}
\hline \multirow{2}{*}{ Sampel } & \multirow{2}{*}{ Umur } & \multirow{2}{*}{ Faktor Reduksi } & $\begin{array}{c}\text { Kuat } \\
\text { Tekan }\end{array}$ \\
\hline & & & $\mathrm{Kg} / \mathrm{cm}^{2}$ \\
\hline 1 & \multirow{6}{*}{28 Hari } & \multirow{2}{*}{ Normal } & 222,222 \\
\hline 2 & & & 242,933 \\
\hline 3 & & \multirow{2}{*}{$\begin{array}{c}21 \% \text { Keramik dan } 7 \% \text { bata } \\
\text { merah }\end{array}$} & 177,911 \\
\hline 4 & & & 189,778 \\
\hline 5 & & \multirow{2}{*}{$\begin{array}{l}10 \% \text { keramik dan } 4 \% \text { bata } \\
\text { merah }\end{array}$} & 204,667 \\
\hline 6 & & & 137,333 \\
\hline
\end{tabular}

Sumber : Analisa Pengamatan

Dari tabel di atas untuk sempel beton normal (1) mempunyai kuat tekan 222,222 kg/cm² ,Beton normal (2) mempunyai kuat tekan $242,933 \mathrm{~kg} / \mathrm{cm}^{2}$, Beton yang mengunakan campuran Keramik 21\% dan bata merah 7\% sempel (1) mempunyai kuat tekan $177,911 \mathrm{~kg} / \mathrm{cm}^{2}$, Beton yang mengunakan campuran Keramik 21\% dan bata merah 7\% sempel (2) mempunyai kuat tekan $189,778 \mathrm{~kg} / \mathrm{cm}^{2}$, Beton yang mengunakan campuran Keramik 10\% dan bata merah $4 \%$ sempel 
(1) mempunyai kuat tekan $204,667 \mathrm{~kg} / \mathrm{cm}^{2}$, Beton yang mengunakan campuran Keramik $10 \%$ dan bata merah 4\% sempel (2) mempunyai kuat tekan $137,333 \mathrm{~kg} / \mathrm{cm}^{2}$. Menujukkan bahwa kuat tekan beton menurun dari menambah volume keramik, di karenakan permukaan keramik tidak bisa mengikat dengan sempurna. Paling tinggi K- 204,667 dengan campuran keramik 10\% dan bata merah 4\% dan beton berumur 28 hari, sedangkan untuk mencapai K-250 sangat jauh sekali. Dari 6 sempel,rata- rata mencapai K-195,807.

\section{KESIMPULAN}

Dari penelitian didapatkan hasil sebagai berikut untuk sempel beton normal (1) mempunyai kuat tekan 222,222 kg/cm,Beton normal (2) mempunyai kuat tekan 242,933 kg/cm, Beton yang mengunakan campuran Keramik $21 \%$ dan bata merah $7 \%$ sempel (1) mempunyai kuat tekan 177,911 kg/cm, Beton yang mengunakan campuran Keramik 21\% dan bata merah 7\% sempel (2) mempunyai kuat tekan 189,778 kg/cm, Beton yang mengunakan campuran Keramik $10 \%$ dan bata merah $4 \%$ sempel (1) mempunyai kuat tekan 204,667 kg/cm, Beton yang mengunakan campuran Keramik $10 \%$ dan bata merah $4 \%$ sempel (2) mempunyai kuat tekan $137,333 \mathrm{~kg} / \mathrm{cm}$. Menujukkan bahwa kuat tekan beton menurun dari menambah volume keramik,di karenakan permukaan keramik tidak bisa mengikat dengan sempurna. Paling tinggi K- 204,667 dengan campuran keramik 10\% dan bata merah $4 \%$ dan beton berumur 28 hari, sedangkan untuk mencapai K-250 sangat jauh sekali. Dari 6 sempel,rata- rata mencapai K-195,807.

\section{SARAN}

Berdasarkan hasil penelitian yang telah dilakukan sebagai bahan pertimbangan, diajukan beberapa saran yaitu perlu dilakukan penelitian lebih lanjut untuk mendapatkan kuat tekan yang lebih besar. Sebaiknya saat melakukan penelitian lanjutan tidak hanya pengaruh kuat tekan beton, ditambah pengaruh penambahan limbah keramik dan batu bata pada beton terhadap kuat tarik

\section{UCAPAN TERIMAKASIH}

Dalam penyusunan artikel ini, penulis ucapkan terimakasih kepada dosen pembimbing dan Universitas Kadiri. Penulis berharap agar artikel ini dapat bermanfaat bagi pembaca.

\section{DAFTAR PUSTAKA}

[1] A. I. Candra and E. Siswanto, "Rekayasa Job Mix Beton Ringan Menggunakan Hydroton Dan Master Ease 5010," J. CIVILA, vol. 3, no. 2, p. 162, 2018, doi: 10.30736/cvl.v3i2.258. 
[2] M. M. Amin, A. D. Limantara, and S. Winarto, "UJI LABORATORIUM PEMANFAATAN BIO ENZIM (BIOCONC) SEBAGAI PEREDUKSI SEMEN PADA BATA BETON MUTU A,”Jurmateks, vol. 1, no. 1, pp. 56-65, 2018.

[3] T. Mulyono, "TEKNOLOGI BETON: Dari Teori Ke Praktek," no. October 2018, p. 574, 2015.

[4] A. Y. Bintoro, A. D. Limantara, and S. Winarto, "EVALUASI KEKUATAN CONCBLOCK DENGAN AGREGAT HALUS DAN AGREGAT KASAR DARI TEMPURUNG KELAPA,”Jurmateks, vol. 1, no. 1, pp. 160-171, 2018.

[5] Badan Standardisasi Nasional, "SNI 03-2834-2000 Tata Cara Pembuatan Rencana Campuran Beton Normal," 2000.

[6] D. Hartanto, Y. Cahyo, S. Winarto, and A. I. Candra, "PERENCANAAN PONDASI TIANG PANCANG PADA GEDUNG SEKRETARIAT DEWAN DPRD KABUPATEN KEDIRI," Jurmateks, vol. 1, no. 2, pp. 303-312, 2018.

[7] Badan Standardisasi Nasional, "SNI 1974:2011 Cara Uji Kuat Tekan Beton dengan Benda Uji Silinder,” 2011.

[8] Badan Standardisasi Nasional, "SNI 3402:2008 Cara Uji Berat Isi Beton Ringan Struktural," 2008.

[9] T. P. G. A, Y. C. S. P, S. Winarto, and A. I. Candra, "PERBANDINGAN KEKUATAN BETON DENGAN CAMPURAN DRAMIX STEEL FIBER DAN TULANGAN WIREMESH PADA RIGID PAVEMENT,” Jurmateks, vol. 1, no. 2, pp. 313-324, 2018.

[10] K. Tjokrodimuljo, “Teknologi Beton,” Biro Penerbit Tek. Sipil Univ. Gajah Mada, 2009.

[11] Badan Standarisasi Nasional, "SNI 2847:2013 Persyaratan Beton Struktural untuk Bangunan Gedung,” 2013.

[12] Badan Standarisasi Nasional, "SNI 03-1750-1990 Mutu dan Cara Uji Agregat Beton," 1990.

[13] ASTM 128, "Standard Test Method for Relative Density ( Specific Gravity ) and Absorption of Fine Aggregate," pp. 1-6, 2016.

[14] Badan Standardisasi Nasional, "SNI 2493:2011 Tata Cara Pembuatan dan Perawatan Benda Uji Beton di Laboratorium,” 2011.

[15] ASTM, “Annual Book of ASTM Standart Volume 04.02 'Concrete and Aggregates,"” no. October 1965, 2003. 
[16] ASTM C 187, "Normal Consistency of Hydraulic Cement," pp. 10-12.

[17] E. Gardjito, A. I. Candra, and Y. Cahyo, "Pengaruh Penambahan Batu Karang Sebagai Substitusi Agregat Halus Dalam Pembuatan Paving Block," UKaRsT, vol. 2, no. 1, p. 35, 2018, doi: 10.30737/ukarst.v2i1.374.

[18] ASTM C 188 - 09, "Standard Test Method for Density of Hydraulic Cement," vol. i, pp. 1-3, 2010, doi: 10.1520/C0188-09.2.

[19] ASTM C 127, "Standard Test Method for Density, Relative Density (Specific Gravity), and Absorption of Coarse Aggregate," pp. 3-8, 2001.

[20] ASTM C 29, "Standard Test Method for Bulk Density (' Unit Weight ') and Voids in Aggregate," vol. 97, no. Reapproved, pp. 3-6, 2003.

[21] ASTM C 39, "Standard Test Method for Compressive Strength of Cylindrical Concrete Specimens," vol. 04, no. March, pp. 1-5, 2001.

[22] ASTM C 33, "Standard Specification for Concrete Aggregates," vol. 04, 2001.

[23] JIS A 1148:2010, "Method of Test for Resistance of Concrete to Freeze and Thawing." .

[24] ASTM 191, "Standard Test Methods for Time of Setting of Hydraulic Cement by Vicat Needle," no. C, pp. 1-8, 2010, doi: 10.1520/C0191-08.2. 